\title{
The Application of Microbiological and Geochemical Exploration in Volcanic Reservoir Exploration
}

\author{
DING LI ${ }^{1,2^{*}}$, WU YUBING ${ }^{2}$, MEI HAI ${ }^{2}$
}

1 China University of Geosciences (Beijing), Beijing 100083, China (*correspondence: realdingli@126.com )

2 AE\&E Geomicrobial Technologies Inc, Beijing 102200, China

Volcanic reservoir is the primary exploration targe in the layer of carboniferoust on the Zhongguai uplift in Junggar Basin. Microbiological and Geochemical Exploration (MGCE) is a sensitive and fast hydrocarbon detection method which is capable of indicating oil and gas distribution and properties by detecting microbial and sorbed soil gas anomalies in surface soil.

By applying MGCE survey in the research area, 3 hydrocarbon accumulation zones were identified, 6 oil and gas prospects were forecasted. The results revealed that MGCE exploration findings matched well with previous drilling result and successfully forecasted 4 oil wells as well as 2 failed wells which were drilled during the microbial survey. By applying the " $4 \mathrm{G}$ " comprehensive research method which combines geology, geophysics, geochemistry and geobiology data for integrated study, 6 microbial anomaly areas were identified in meso basaltic volcanic development area, this finding matched well with the palaeo salients in carboniferous. 3 wells were drilled on 3 of those microbial favorable areas post $4 \mathrm{G}$ integrated research. The testing result showed that all 3 wells are capable of commercial production, the productivity of each well was respectively $2 \mathrm{~m}^{3}, 37 \mathrm{~m}^{3}$, $64.9 \mathrm{~m}^{3}$ per day after fracturing. The application of new technology provided new exploration model for the exploration of volcanic reservoir and the $4 \mathrm{G}$ exploration method is expected to be an effective new way to explore complex reservoirs.

Key Words: Microbial, Vocanic Reservoir, "4G” research 